EMBRYARIDDLE
Aeronautical University

SCHOLARLY COMMONS
International Journal of Aviation, Aeronautics, and Aerospace

\title{
Qualitative Analysis of Loss of Control Aircraft Accidents Using Text Mining Techniques
}

\author{
Carolina Anderson \\ Embry-Riddle Aeronautical University - Daytona Beach, lenzc@erau.edu \\ MaryJo O. Smith \\ Ypsilon Associates, drmaryjosmith@gmail.com
}

Follow this and additional works at: https://commons.erau.edu/ijaaa

Part of the Aerospace Engineering Commons, and the Aviation Commons

\section{Scholarly Commons Citation}

Anderson, C., \& Smith, M. O. (2017). Qualitative Analysis of Loss of Control Aircraft Accidents Using Text Mining Techniques. International Journal of Aviation, Aeronautics, and Aerospace, 4(4). https://doi.org/ 10.15394/ijaaa.2017.1095

This Article is brought to you for free and open access by the Journals at Scholarly Commons. It has been accepted for inclusion in International Journal of Aviation, Aeronautics, and Aerospace by an authorized administrator of Scholarly Commons. For more information, please contact commons@erau.edu. 
Qualitative Analysis of Loss of Control Aircraft Accidents Using Text Mining Techniques

\section{Cover Page Footnote}

Study based on author's Ph.D. Dissertation 
The objective of this study was to analyze the narrative National Transportation Safety Board (NTSB) accident cause descriptions for general aviation (GA) Loss of Control (LOC) accident reports by the different certification categories: 14CFR 23 (Part 23), Civil Air Regulations 3 (CAR 3), Light Sport Aircraft (LSA), and Experimental-Amateur Built (E-AB). These results helped comprehend and extend the findings of a quantitative analysis conducted to understand the association of aircraft certification rules on GA mishaps (Anderson, 2013; Anderson, 2015) ${ }^{1}$. The main objective of this study is to explain and illustrate how text mining techniques were used to analyze the qualitative portion of the accident reports.

\section{Background}

Aircraft certification regulations are intended to ensure the airworthiness of aircraft by requiring manufacturers of aircraft and aircraft components to comply with approved aircraft designs, maintenance requirements, and operational limitations in order to increase the reliability of safety-critical systems (Committee on Aircraft Certification Safety Management [CACSM], 1998). While strict certification requirements represent high standards for aircraft manufacturers, in the last three decades new GA aircraft certification costs have increased, the number of GA aircraft produced has decreased, and there has been no accompanying substantial changes in operational safety or accident rates (Bowles, 2010).

The Federal Aviation Administration (FAA) regulations that govern today's aircraft are described in Title 14 of the Code of Federal Regulations (14 CFR) (Federal Aviation Administration [FAA], 2013). Standards pertaining to airworthiness and type-certification for airplanes with a certificated takeoff weight, not in excess of 19,000 pounds ${ }^{2}$ in the normal, utility, and aerobatic categories are specified in 14 CFR Part 23 (Part 23) regulations (FAA, 2013). The latter covers a broad spectrum of airplanes that range from a Piper Cub type airplane to a business jet. Airplanes certificated under these regulations are often used for recreation, instruction, personal travel, and limited commercial applications.

Since the 1980s, the regulatory scope of Part 23 has been shifted to address increasingly sophisticated aircraft, placing an excessive burden on the certification

\footnotetext{
${ }^{1}$ The aforementioned study was part of author's dissertation (Anderson, 2013) and the quantitative portion was published in a journal paper (Anderson, 2015).

${ }^{2}$ Part 23 also includes multiengine airplanes in the commuter category with a maximum certificated takeoff weight of 19,000 pounds or less and a seating configuration, excluding pilot seats, of 19 or less.
} 
of simpler aircraft. Towards this end, the FAA has made use of special conditions and issue papers (unsure what your meaning is here Carolina) to assure continued safety in view of regulations that have failed to keep pace; these processes have substantially increased the administrative burden to both FAA staff and applicants. As a result, certification costs have grown exorbitantly, ultimately culminating in fewer entry products into the light airplane marketplace. In 2009, the FAA initiated a Part 23 Certification Process Study (CPS) to determine the adequacy of the existing certification and airworthiness standards processes (FAA, 2009). Following the recommendations of the CPS in August 2011, the FAA created a Part 23 Aviation Rulemaking Committee (ARC) (FAA, 2011b).

Tasking for the ARC also included a re-write of the regulations on a broad, general, and progressive level (FAA, 2009). The ARC meetings were concluded in January of 2013; the recommendations of the ARC were submitted to the FAA in May of 2013 (Pompeo, 2013), and a Notice of Proposed Rulemaking (NPRM) was issued on March 9, 2016 (Airworthiness Standards for Normal, Utility, Acrobatic, and Commuter Category Airplanes, 2016). One of the recommendations from the ARC was to develop a set of industry consensus standards that would integrate into a modified certification approval process of the new Part 23 regulations (Part 23 ARC, 2012). As a result of the ARC meetings, a new GA aircraft certification chapter was created within an international consensus standards organization, American Standards for Testing and Materials (ASTM), ASTM F44.

The use of industry consensus standards is consistent with Public Law 104113, also known as the National Technology Transfer and Advancement Act of 1995 (NTTAA) (National Technology Transfer and Advancement Act [NTTAA], 1996). NTTAA encourages federal agencies in the U.S. wherever possible, to utilize standards developed by voluntary consensus standards bodies rather standards established by the government.

In the early 2000s, GA advocacy groups, such as the Experimental Aircraft Association (EAA) and the General Aviation Manufacturers Association (GAMA), became concerned with rising certification costs and dwindling pilot populations. As a result, these advocacy groups petitioned the FAA to apply NTTAA to an aviation case. In 2004, the FAA initiated a test case with the certification of a new aircraft category, Light Sport Aircraft (LSA), utilizing consensus standards (Bowles, 2010). Two categories within the LSA class were created: Special-Light Sport Aircraft (S-LSA) and Experimental-Light Sport Aircraft (E-LSA). ASTM was chosen for the implementation and management of the LSA industry consensus standards. Early indicators show that the LSA category has helped revitalize the industry; the pilot population had increased by 4,066 pilots since 2004 when the 
new LSA rules were implemented. This figure represents a substantial contribution to an industry in which the total active pilot population has been dwindling over the last decade (GAMA, 2012); thus, the propagation of consensus standards to more mainstream uses has become an appealing option applicable to other segments of aviation (FAA, 2009).

In the U.S., piston airplanes account for $67 \%$ of the total civil aviation aircraft population, followed by experimental airplanes at $11 \%$ (Figure 1). However, the annual production count of piston airplanes has shown a continuous downward trend over the years. Based on GAMA (2012) data, while the U.S. manufactured 15,594 piston aircraft in 1947 this number decreased by more than $90 \%$ (to 1,514) by 2012 (see Figure 2).

The decreased piston airplane production in the U.S. from 1947 to 2012, can be attributed to many factors such as (a) the re-distribution of the market share with the introduction of turboprop and jet airplanes, (b) the evolution of the product liability law, (c) natural disasters, (d) wars, (e) terrorist attacks, (f) economic downturns, (g) increasing fuel prices, and (h) rising certification costs (FAA, 2009; GAMA, 2012; Shetty \& Hansman, 2012).

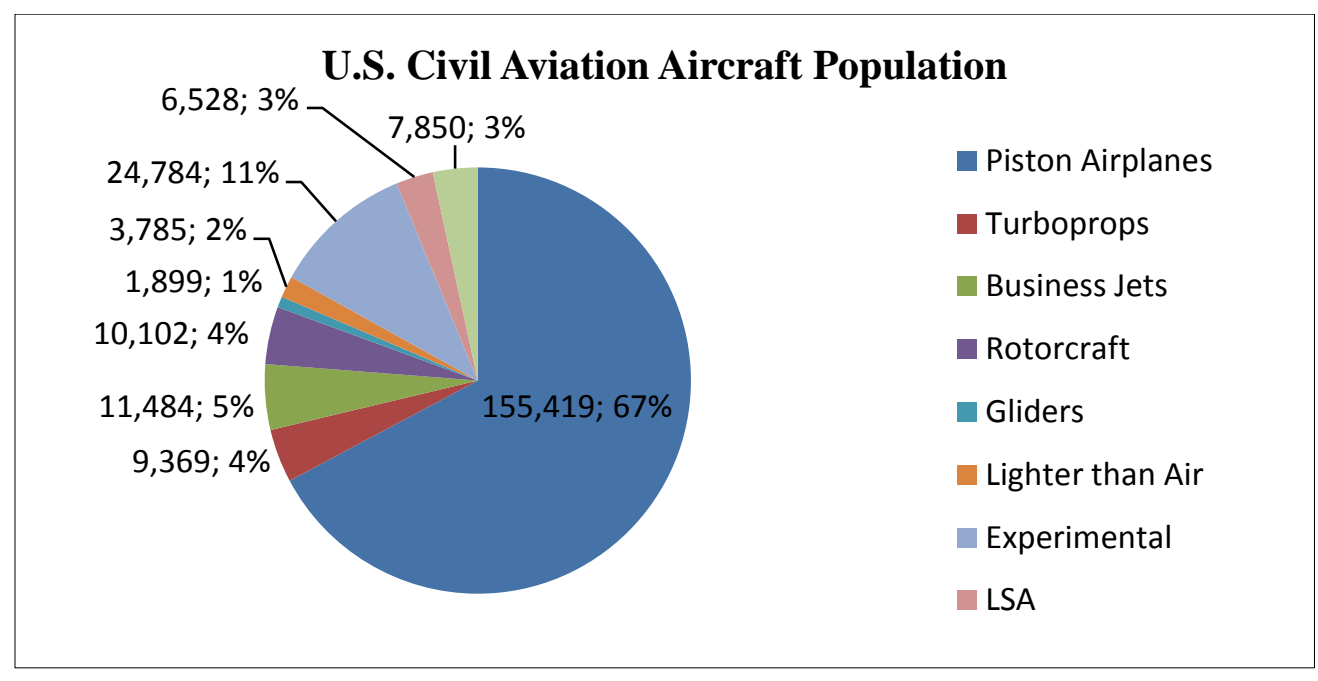

Figure 1. U.S. civil aviation aircraft population. Adapted from General Aviation Statistical Databook and Industry Outlook by GAMA, 2012 and Small Airplanes by G. Bowles, 2012. 


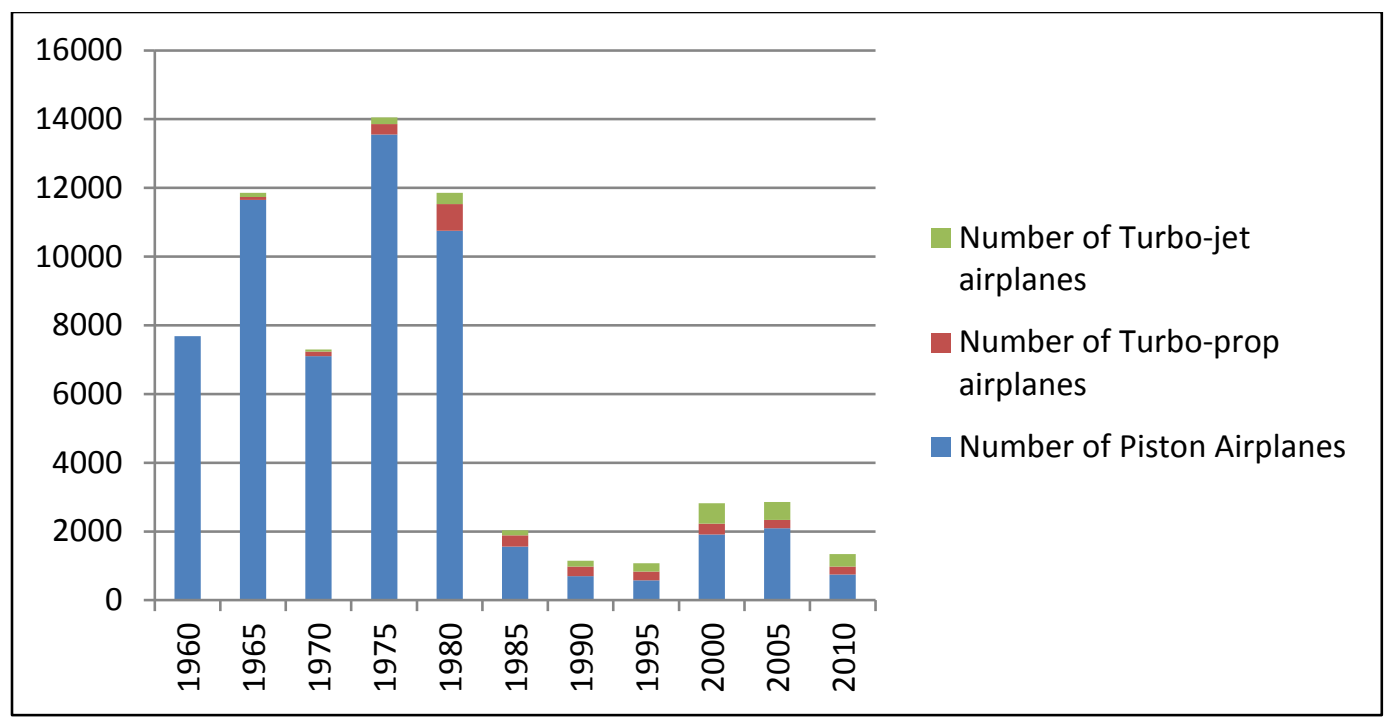

Figure 2. U.S. Part 23 airplanes manufactured annually. Adapted from General Aviation Statistical Databook and Industry Outlook by GAMA, 2012.

Part 23 certified entry-level two-seat and four-seat airplanes are essential in pilot flight training. The price of new entry-level airplanes has increased at a much higher rate than the standard inflation. The few new, certified entry-level airplanes that are produced come at a very high cost due to the lengthy and expensive certification requirements. As a result, the average age of the GA fleet is over 40 years (GAMA, 2012). Retrofitting these old aircraft with new technologies would involve a lengthy and expensive re-certification process, which inhibits many pilots from taking advantage of new technologies. Due to the stringent Part 23 regulatory requirements, these older aircraft designs cannot accommodate the new safety technologies that have become common such as Ballistic Recovery Parachutes (BRS) and airbags (FAA, 2009).

In 2012, the U.S. had 188,001 private pilots compared to 1992 when the private pilot population was at 288,078 (GAMA, 2012), which is a decrease of over 100,000 private pilots between 1992 and 2012. The sport pilot certification was established when the new LSA rules were implemented. The LSA category of aircraft and their associated sport pilots represent a significant contribution to an industry in which the total active pilot population has been dwindling over the last decade at an average rate of 10,000 pilots per year (GAMA, 2012). The sport pilot population continues to increase with a 10\% more sports pilots in 2012 (GAMA, 2012). 
As of 2013, there were 13 aircraft manufacturers of Part 23 certified twoseat or four-seat piston aircraft in the U.S. (GAMA, 2012); most of these Part 23 aircraft manufacturers have been in operation for over 30 years. Since the creation of the LSA category in 2004, 20 new U.S. manufacturers of LSA aircraft have emerged (Johnson, 2013). The pilot population had increased by 4,066 pilots since 2004 when the new LSA rules were implemented. This figure represents a significant contribution to an industry in which the total active pilot population has been dwindling over the last decade (GAMA, 2012). Part 23 has also been the entry point for many new aircraft technologies, including composite materials, satellite navigation and approaches, integrated glass cockpits, synthetic vision, and Automatic Dependent Surveillance-Broadcast (ADS-B) (Bowles, 2010).

The Experimental-Amateur Built (E-AB) category constitutes the fastest growing segment of the GA fleet in the U.S. (U.S. Government Accountability Office [GAO], 2012). One of the main advantages for people to acquire an E-AB, or convert a certified aircraft to the experimental category, is that owners can make modifications to an aircraft without any coordination with the manufacturer (McClellan, 2013). E-AB aircraft is defined by the FAA as aircraft in which at least $51 \%$ of the aircraft was fabricated and assembled by a sole person or group and undertaken with the goal of education or recreational activity.

In 2011, approximately 33,000 E-AB aircraft were registered, a $10 \%$ increase from 2008; thereby making the E-AB aircraft the fastest growing segment of the GA fleet (National Transportation Safety Board [NTSB], 2012a). On the other hand, the number of accidents involving $\mathrm{E}-\mathrm{AB}$ aircraft has increased since 1999 through 2011; E-AB aircraft accounted for 14\% of airplanes in nonfatal GA accidents and approximately $21 \%$ of fatal accidents. In 2012, the NTSB completed a safety study of E-AB aircraft. Among other findings, the NTSB concluded that the first 50 hours of flight, known as the flight test period for E-AB airplanes, are uniquely challenging for most pilots (NTSB, 2012b).

\section{Primary causes of general aviation accidents}

According to the FAA (2011a), from 2010 to 2012, fatal accidents from CFIT have been reduced by more than $50 \%$ referencing the prior three years. Fatal accidents involving LOC in flight, during approach, and during landing have decreased between 20 to $25 \%$. Meanwhile, fatal accidents caused by bad weather have declined by nearly $40 \%$ in the past three years, and fatal accidents occurring at night decreased approximately $25 \%$. The FAA attributes these reductions in fatal accidents to the use of technology such as Global Positioning System (GPS) with moving maps and in-flight weather capabilities. New technologies such as 
inflatable restraints, ballistic parachutes, data-link weather in the cockpit, Angle of Attack (AOA) indicators, traffic alert systems, and terrain avoidance equipment could continue reducing GA accidents with a fatal outcome if these technologies are allowed to be implemented in certified airplanes. The FAA is making an effort to facilitate the approval process of AOA indicators and seatbelts with airbags in order to allow all GA aircraft to be eligible for the installation of these devices (FAA, 2011a).

In a further effort to reduce GA accidents, the General Aviation Joint Steering Committee (GAJSC) was formed circa 1995 and is currently renewing its accident reduction efforts. The GAJSC is a government and industry group that uses a data-driven, consensus-based approach to analyze safety data to develop specific methodologies towards identifying the root cause of mishaps and according to diminishing accident rate. The group released recommendations to address LOC during approach and landing (General Aviation Joint Steering Committee [GAJSC], 2012). The report addresses the current Part 23 certification problems and emphasizes the importance of incorporating new technologies to prevent accidents. CFIT fatal accidents dropped 60\% between 2001 and 2010; the GAJSC (2012) attributes that improvement to the use of electronic information such as situational awareness via GPS-moving maps, near-real-time weather, terrain awareness, and traffic proximity alerts. These electronic devices have made a considerable contribution to the reduction of pilot workload. The GAJSC (2012) also emphasizes that most of the safety-enhancing technology that diminished the CFIT mishap rate was via handheld-rather than panel-mounted equipment.

The GAJSC (2012) also recommended the use of AOA indicators and autopilots to prevent LOC accidents; unfortunately, these technologies are not available in the form of handheld equipment. Therefore, the substantial expense of certification and installation is a strong deterrent to their integration into light aircraft. Indeed, the report also states that the cost of installing an existing AOA system on a certified airplane is almost 10 fold in excess of a comparable installation into an experimental airplane.

According to the GAJSC (2012), LOC accidents during non-daytime hours and in Instrument Meteorological Conditions (IMC) would be reduced by half by the installation of autopilots in the more than 100,000 airplanes approved for Instrument Flight Rules (IFR). Again, autopilots can be installed in experimental airplanes for as low as $\$ 2,500$; however, installing an autopilot on a certified airplane could cost at least $\$ 10,000$, which represents between 10 to $50 \%$ of the average value of a GA airplane. The GAJSC (2012) report also recommended that the FAA employ a risk management approach for analyzing whether existing 
certification regulations deter owners/operators from the installation of such a safety-enhancing technology.

\section{Summary of Previous Quantitative Study}

A quantitative analysis of the National Transportation Safety Board (NTSB) accident reports was conducted to understand the effects of aircraft certification rules on GA accidents (Anderson, 2013; Anderson, 2015). Subsequently, a qualitative analysis of the NTSB accident report narratives was performed utilizing text mining techniques to analyze the narrative causes within the NTSB accident reports of accidents where Loss of Control (LOC) was listed as a cause. The qualitative results helped explain the initial results of the quantitative analysis. The main objective of this paper is to explain and illustrate how text mining techniques were used to analyze the qualitative portion of the accident reports to gain a better understanding of the quantitative part of the research.

The research focused on the overarching hypothesis that there is no significant difference in the frequency of accidents caused by LOC for the period spanning January 1, 2004, to December 31, 2011, between airplanes certified via Part 23, CAR 3, LSA, or E AB categories. The quantitative portion of the study consisted of two parts. In the first part, a Chi-Square statistical test was performed to compare the frequencies of LOC-related mishaps (occurring between 2004 and 2011) between airplane certification groups (Part 23, CAR 3, LSA, or E-AB). In the second part, an ANCOVA statistical test was utilized to compare the LOCrelated accident rates among airplanes certified by the aforementioned mechanisms across the identical time period.

For the ANCOVA statistical test, the dependent variable used was accident rate. The accident rate was calculated by dividing the number of annual accident count for each of the aircraft airworthiness categories by the fleet time for each category; these data were obtained from the GA activity survey (GAMA, 2012). The fixed factor or independent variable used was airworthiness certification basis. In order to account for pilot experience, design stage of the airplane, and age of the airplane, the number of hours on the airplane's airframe and the number of hours of total flight time of the pilot were used as covariates. Covariates are not part of the dependent or independent variables but have the potential to have an influence on the dependent variable (Field, 2009).

Hypothesis testing. The purpose of the quantitative study (Anderson, 2013; Anderson, 2015) was to compare airplane safety based on aircraft certification to determine whether the latter affected the former. The certification categories 
examined were: Part 23, CAR 3, LSA, and E-AB. The accident cause examined was LOC for occurrences spanning the January 1, 2004-December 31, 2011, period.

The hypotheses were:

$\mathrm{H}_{0} 1$ : There is no significant difference in the frequency of accidents between airplanes certified in the various categories (Part 23, CAR 3, LSA, or E-AB) and for which LOC was listed as causal.

$\mathrm{H}_{0} 2$ : For the period spanning 2004-2011, there is no significant difference in the LOC-related accident rate between airplanes certified in the aforementioned categories 2004 to 2011.

Quantitative Analysis Results. Table 1 shows the frequency of accidents, number of active aircraft, hours flown, and accident rate by certification basis. The accident rate for the LSA and E-AB categories for accidents in which LOC was listed as a cause is higher than for Part 23 category airplanes, even though Part 23 airplanes account for 814 accidents in which LOC was listed as a cause, and LSA airplanes were only involved in 75 accidents in which LOC was listed as a cause between the years of 2004 and 2011.

Table 1. Frequency of Accidents by Cause and Certification Basis for all Accidents from 2004-2011.

\begin{tabular}{llllll}
\hline $\begin{array}{l}\text { Cause/Cert. } \\
\text { Basis }\end{array}$ & CAR 3 & Part 23 & E-AB & LSA & Total \\
\hline LOC & 618 & 196 & 266 & 75 & 1,155 \\
\hline
\end{tabular}

Table 2 shows the frequency of accidents, number of active aircraft, hours flown, and accident rate by certification basis. The accident rate for the LSA and $\mathrm{E}-\mathrm{AB}$ categories for accidents in which LOC was listed as a cause is higher than for Part 23 category airplanes, even though Part 23 airplanes account for 814 accidents in which LOC was listed as a cause, and LSA airplanes were only involved in 75 accidents in which LOC was listed as a cause between the years of 2004 and 2011.

Hypothesis testing Results: Ho1. For LOC-related accidents between 2004 and 2011, the null hypothesis tested was that there was no significant difference in the frequency of accidents between airplanes certified in the various 
categories described 2004 to 2011 . The Chi-Square test result was $\chi^{2}=65.75, d f=$ 9 , and $p=.000$; therefore, the null hypothesis was rejected.

Table 2. Frequency of Accidents, Active Airplanes, Hours Flown, and Accident Rate by Cause and Certification Basis for 2004-2011.

\begin{tabular}{llllll}
\hline $\begin{array}{l}\text { Accident } \\
\text { Cause }\end{array}$ & Cert. Basis & $\begin{array}{l}\text { No. } \\
\text { accident } \\
\text { s }\end{array}$ & $\begin{array}{l}\text { Hours } \\
\text { Flown }\end{array}$ & $\begin{array}{l}\text { No. } \\
\text { Active } \\
\text { Airplane } \\
\text { s }\end{array}$ & $\begin{array}{l}\text { Accident } \\
\text { Rate }\end{array}$ \\
\hline LOC & PART & 814 & $106,850,03$ & 149,711 & $7.62 \mathrm{E}-06$ \\
& 23/CAR 3 & & 1 & & \\
& LSA & 75 & $1,581,539$ & 4,545 & $4.74 \mathrm{E}-05$ \\
& E-AB & 266 & $7,392,719$ & 21,106 & $3.60 \mathrm{E}-05$ \\
\hline
\end{tabular}

For CAR 3 airplanes, there were 618 LOC accidents between 2004 and 2011, with a decreasing trend of 105 accidents in 2004 to 59 accidents in 2011 that represents a $43 \%$ decrease in seven years. For CAR 3 airplanes, the standardized residual that fell outside of the \pm 1.96 range was for the years 2004/2005 with a value of 2.4; the actual number of accidents were higher than the expected values for that period. For Part 23 airplanes, there were 196 LOC accidents between 2004 and 2011, with a decreasing trend of 28 accidents in 2004 to 19 accidents in 2011 that represents a $32 \%$ decrease in seven years. For Part 23 airplanes, there were no standardized residuals that fell outside of \pm 1.96 range. For E-AB airplanes, there were 266 LOC accidents between 2004 and 2011, with a decreasing trend of 41 accidents in 2004 to 19 accidents in 2011 that represents a 53\% decrease in seven years. For E-AB airplanes, there were no standardized residuals that fell outside of \pm 1.96 range.

As expected, there was an increase in LOC accidents for the LSA category from 0 accidents in 2004 to 18 accidents in 2011 with a total of 75 LOC accidents between 2004 and 2011. For LSA airplanes, the standardized residuals that fell outside of \pm 1.96 range were for the years 2004/2005 with a standardized residual value of -4.6, 2005/2006 with a standardized residual value of 2.1, and 2010/2011 with standardized residual value of 4.5; the negative value of the 2004/2005 residual indicates that the actual number of accidents was lower than expected. During 2005/2006 and 2010/2011, the number of accidents was higher than the expected. 
Hypothesis testing Results: Ho2. For LOC-related accidents, Levene's test of equality of error variances, assessing the homogeneity of variances was not significant ( $\mathrm{p}=.053$ ); therefore, the assumption was met. The null hypothesis tested was that the LOC-related accident rate (2004-2011) between airplanes certified in categories listed above, was not significantly different. The main effect, aircraft certification basis, was not statistically significant with $F(2,3)=.71, p=0.560$. Therefore, there was no significant difference among aircraft accidents based on aircraft certification basis in accidents in which LOC was listed as a cause. The interactions between pilot flight time and time on the airframe with aircraft certification basis were also not significant. The $F$-statistic in the ANCOVA test had a probability greater than $.05(p=.560)$; therefore, the null hypothesis failed to be rejected (see Table 3 ).

Table 3. ANCOVA as a Function of Certification Basis with Hours on the Airplane's Airframe and Pilot Total Flight Time as Covariates for LOC Accidents.

\begin{tabular}{lllllll}
\hline Source & df & MS & F & Sig. & $\mathbf{\eta}^{2}$ & eta \\
\hline Cert. Basis & 2 & $1.90 \mathrm{E}-10$ & .71 & .560 & .32 & .56 \\
Cert. Basis * pilot flt. time & 3 & $3.86 \mathrm{E}-10$ & 1.44 & .386 & .59 & .77 \\
Cert. Basis * airframe time & 3 & $7.52 \mathrm{E}-10$ & 2.80 & .210 & .74 & .86 \\
Error & 3 & $2.69 \mathrm{E}-10$ & & & & \\
& & & & & & \\
\end{tabular}

\section{Method}

The current study focused on analyzing GA accidents involving fixed-wing, single-engine aircraft. The research concentrated on comparing LOC airplane accidents based on airworthiness certification. The airworthiness categories utilized in the study were Part 23, CAR 3, LSA-that includes E-LSA and S-LSA-, and E$\mathrm{AB}$. The time period selected for the accident occurrences was between January 1, 2004, and December 31, 2011, so as to include the LSA category that was created in 2004.

LOC accidents are of particular interest because they are the main predominant cause of GA mishaps (Stephens, 2012). LOC is of special concern to the FAA as it relates to aircraft certification because the GAJSC (2012) recommended the use of AOA indicators and autopilots to prevent LOC accidents; however, these technologies, for the most part, must be installed in the airplane and 
are not available in the form of handheld equipment. The high cost of certification and installation deters airplane owners and operators from incorporating these technologies in small GA airplanes. The GAJSC (2012) also stated that the cost of installing an after-market AOA system on a certified airplane is approximately 10 fold higher than installing the same system on an experimental airplane.

\section{Research Approach}

The study consisted of the analysis of text contained in the narrative section of accident investigation reports utilizing text mining techniques. Text mining uses a variety of technologies for analyzing and processing textual data either in unstructured for semi-structured forms (Nisbet, Elder, \& Miner, 2009). Powerful algorithms are used to turn text into numbers extracted from large document databases. Singular Value Decomposition (SVD) is the specific text mining method utilized for this study. SVD is a method of representing a matrix as a series of linear approximations that expose the underlying meaning/structure of the matrix (Nisbet, Elder, \& Miner, 2009). The goal of SVD is to find the optimal set of factors that best predict the outcome (unable to help here as not familiar with text-mining). SVD is similar to principal component analysis in that it reduces the dimensions of the input matrix to a much smaller matrix with fewer variables. Following SVD, clustering is applied to the data. Clustering is a process in which objects are placed into groups. The clustering method used in this study was the scatter/gather method.

Design and procedures. Text mining techniques were used to analyze the qualitative portion of the NTSB accident reports, more specifically the narrative cause section. These narratives consisted of a few sentences or a few paragraphs of text depending on the complexity and nature of the accident. The information in the narrative cause section can vary within the database as (a) different reporters may include various levels of detail, and (b) different causes and factors leading to the accident are confined within the narrative. Text mining can help identify sets of words of similar meaning from the narrative cause section of the report; it can also identify clusters of similar circumstances, potential patterns, and relationships between accidents (Nisbet, Elder, \& Miner, 2009).

\section{Population and Sample}

The population for the study consisted of all U.S. fixed-wing, single-engine, reciprocating-piston airplanes with a certificated takeoff weight not exceeding 12,500 pounds that have been involved in a LOC accident. The sample was comprised of LOC-related mishaps occurring over the period spanning January 1, 2004- December 31, 2011, involving -fixed-wing airplanes (i) powered by a single 
reciprocating engine (ii) and have a maximum certificated takeoff weights did not exceed 12,500 pounds. The airworthiness certification categories used for the study were: (a) standard category, which also includes normal, utility, and aerobatic; (b) LSA that includes E-LSA and S-LSA; and (c) amateur-built airplanes within the experimental category. The airworthiness categories excluded from the sample were limited, restricted, special flight, provisional, transport, and unknown. The start date (Jan 1, 2004, reflecting the establishment of the LSA category in that year. The end date (Dec 31, 2011) reflected the publication of the final NTSB report inclusive of a probable cause

\section{Sources of the Data}

The sources of data to obtain the airplane accident information were (a) the publicly available NTSB aviation accident database downloaded in Microsoft Access ${ }^{\circledR}$ format and (b) the FAA type-certification data sheets. The FAA type certificate database was used to determine the aircraft certification basis.

Qualitative data. The qualitative data for the study was extracted from the narrative cause section of the NTSB accident investigation reports. The qualitative results are exploratory and not causal but are a great tool to fill the gap between initial quantitative results (Teddie \& Tashakkori, 2009). Text mining techniques were utilized to help analyze the qualitative portion of the NTSB accident reports and explain the results of the quantitative portion of a previous study-see summary of quantitative study section- (Anderson, 2013; Anderson, 2015).

The Text Mining function of the STATISTICA Data Mining Software was utilized to analyze the dataset using text mining techniques. This text mining function aids in the identification of the main words encountered in the document along with their frequency. SVD was used to limit the count of variables to an arbitrarily-set number of, linear combinations that extract the maximum information.

A variety of plots are available including a scree plot and a scatter plot. The scree plot indicates the different dimensions and the percentage of the total variance. The elbow or point of inflection of the scree plot indicates the point where the squared singular values across subsequent dimensions become very shallow and the smooth decrease of singular values levels off; it represents words or concepts that appear most frequently. Following the SVD and after identifying the most important concepts, these concepts are plotted against each other in a scatter plot. The scatter plot allows for the identification of word groups or clusters. 
Delimitations. The entry-level airplanes within Part 23 have been identified by the FAA (2009) as being the most affected by the increased difficulty and cost of certification. Aircraft certified under Part 23 is limited to a passenger seating capacity of nine or less, except for the commuter aircraft within Part 23 that have a maximum passenger seating capacity of 19 passengers. In order to compare airplane accidents based on certification basis, Part 23, LSA, LSA, and E-AB, the complexities and missions of these aircraft have to be comparable; therefore, this study focused on studying accidents involving airplanes defined as fixed-wing, single-engine, reciprocating-piston airplanes. By limiting the type of operation to non-commercial operations or FAR Part 91 operations that include personal use and flight instruction, the missions of the airplanes utilized in the study were similar. The time period selected was between January 1, 2004, and December 31, 2011, in order to include the LSA category that was created in 2004.

Limitations. The number of accidents in which LOC was listed as a cause for the LSA category was 75 . The LSA category began in 2004, and there were a total of LSA 4,545 airplanes for the period of 2004 to 2011.

\section{Results}

Text mining was utilized to analyze the qualitative portion of the NTSB accident reports, specifically the narrative cause. Only accidents in which LOC was listed as a cause were analyzed using text mining because LOC is the number one cause of accidents in GA.

Text mining analysis for all aircraft certification categories in which LOC was listed as a cause. Text mining was first conducted to analyze the narrative text of all LOC-caused aircraft accidents across the combined categories (Part 23, CAR 3, LSA, and E-AB). A total of 1,155 narratives were analyzed. Figure 3 shows the scree plot for the singular value decomposition analysis. The graph indicates that the first four concepts account for more than $50 \%$ of the singular value decomposition, giving the highest percent explanation of the singular values.

Figure 4 shows the scatter plot graph for the concepts extracted from the singular value decomposition. The scatter plot appears to have three well-defined groups of words or clusters. Figure 5 shows a closer view of cluster 1 . Cluster 1 seems to have two sub-clusters. The common words within cluster 1a are tailwind, runway, mush, gust high, direct, delay, recovering, bounce, speed, final, flare, maintain, and inability. This cluster appears to be associated with the take-off and landing phases of flight and involves un-stabilized approaches during windy/gusty conditions. The words within cluster $1 \mathrm{~b}$ are fog, thunderstorm, limit, known, 
adverse, cruise, dark, ceiling, and Visual Flight Rules (VFR). This cluster appears to be associated with cruise conditions in which adverse weather was a factor.

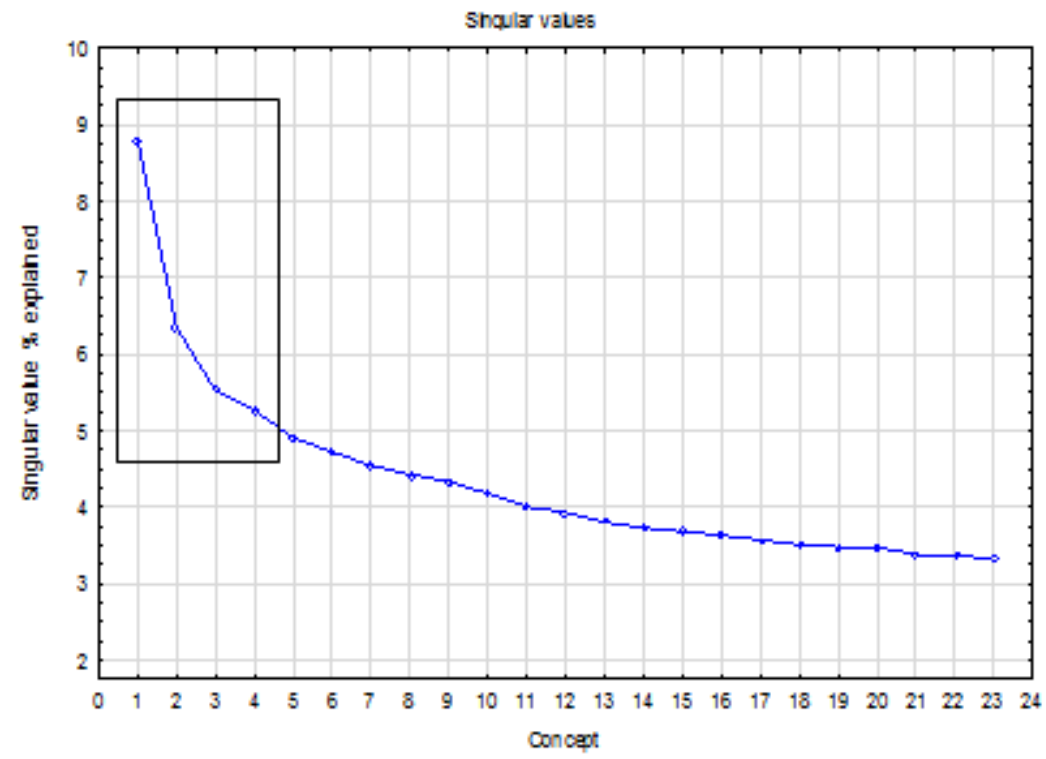

Figure 3. Scree plot for text mining analysis for all aircraft certification categories in which LOC was listed as a cause.

Cluster 2 includes the following words: instructor, failure, maintain, contributing, factor, airspeed, stall, maneuver, and improper. This cluster is mostly associated with maneuvering flight, in most cases involving an instructor on-board, in which the contributing factor was failure to maintain appropriate airspeed resulting in a stall.

Cluster 3 included the words: in-flight, loss, control, weather meteorological, instrument, condition, continued, lack, experience, plan, night, low, and ice. This cluster is mostly associated with accidents involving flight into instrument meteorological conditions, mostly at night in low visibility, and in many cases, in icing conditions where planning, lack of experience and decision making was a factor. 


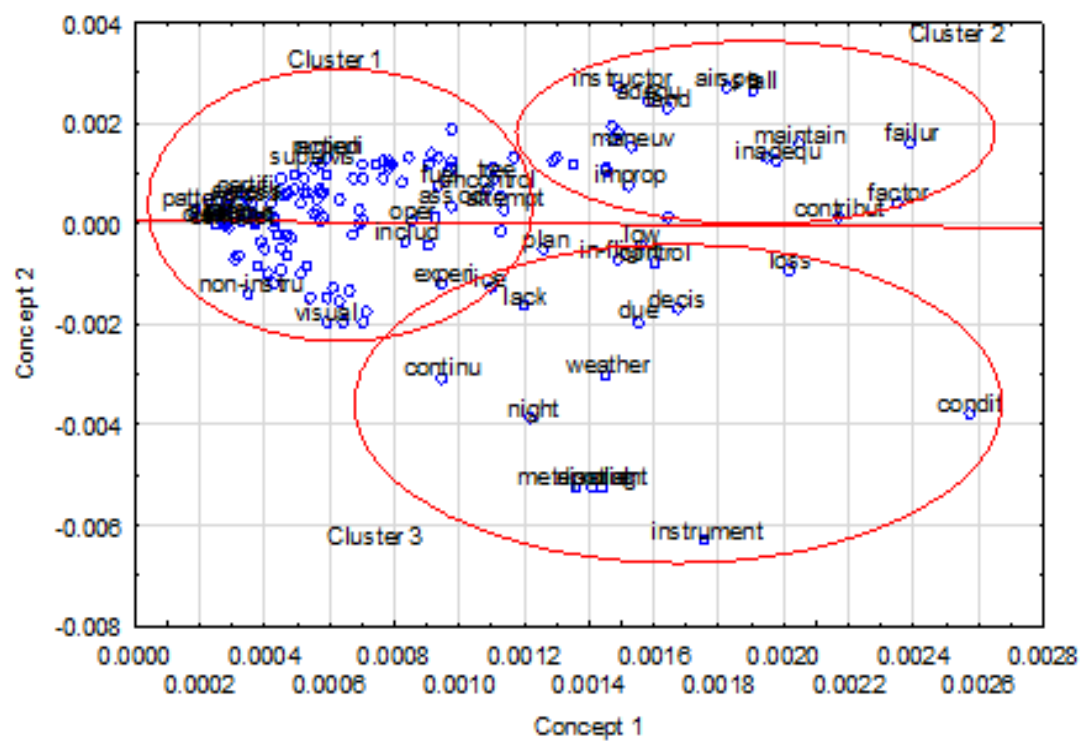

Figure 4. Scatter plot with clusters for text mining analysis of LOC accidentssample: 1,155 narratives.

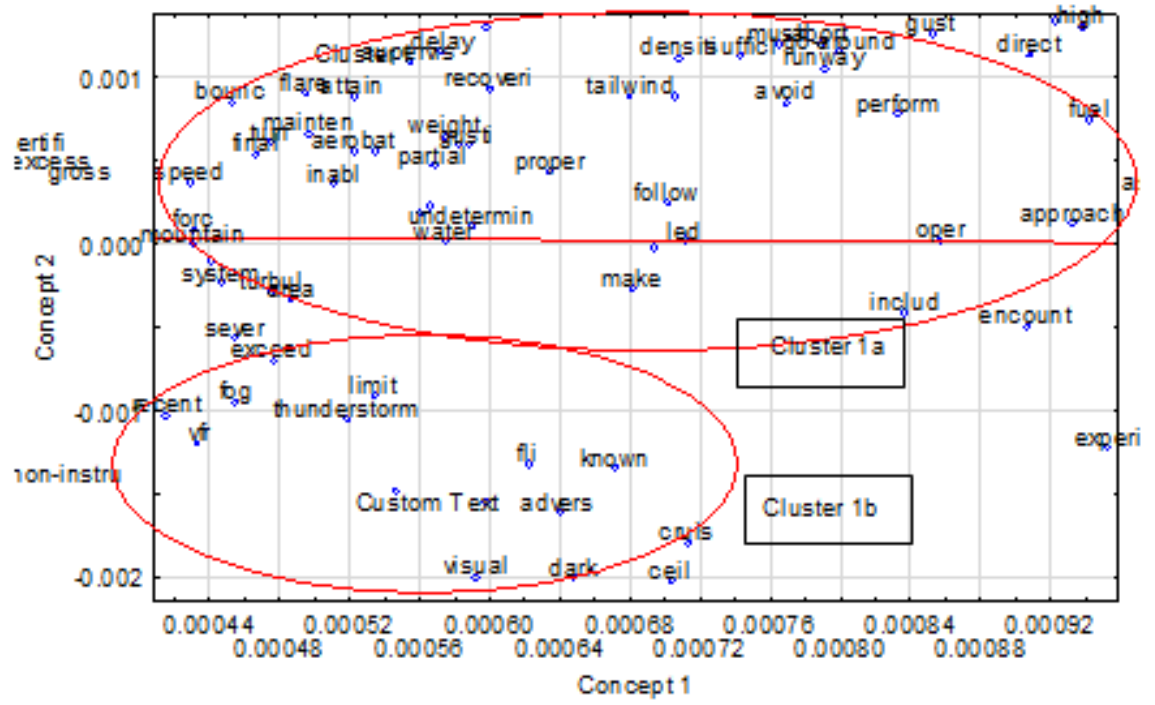

Figure 5. Cluster 1 detail of scatter plot with clusters for text mining analysis of LOC accidents. 
Text mining analysis for E-AB airplanes in which LOC was listed as a cause. A total of 266 narratives were analyzed. Figure 6 shows the scatter plot graph for the concepts extracted from the singular value decomposition. The scatter plot appears to have three well-defined clusters of words. Cluster 1 includes the words undetermined and takeoff; the narratives for these words refer to most accidents during the takeoff phase of flight that resulted in a stall and spin due to undetermined reasons. Cluster 2 includes the words: maneuver, in-flight, collision, and terrain; a closer look into the narratives that include these words reveal that $6.25 \%$ of the E-AB accidents in which LOC was listed as a cause involved low altitude maneuvering and $7.8 \%$ of the E-AB accidents in which LOC was listed as a cause involved aerobatics. Cluster 3 included the words: land, aerodynamic, stall spin, pilot's failure to maintain, airspeed, lack, and inadvertent. This cluster is mostly associated with accidents involving the landing phase of flight in which the airman's failure to maintain sufficient airspeed resulted in a stall and spin.

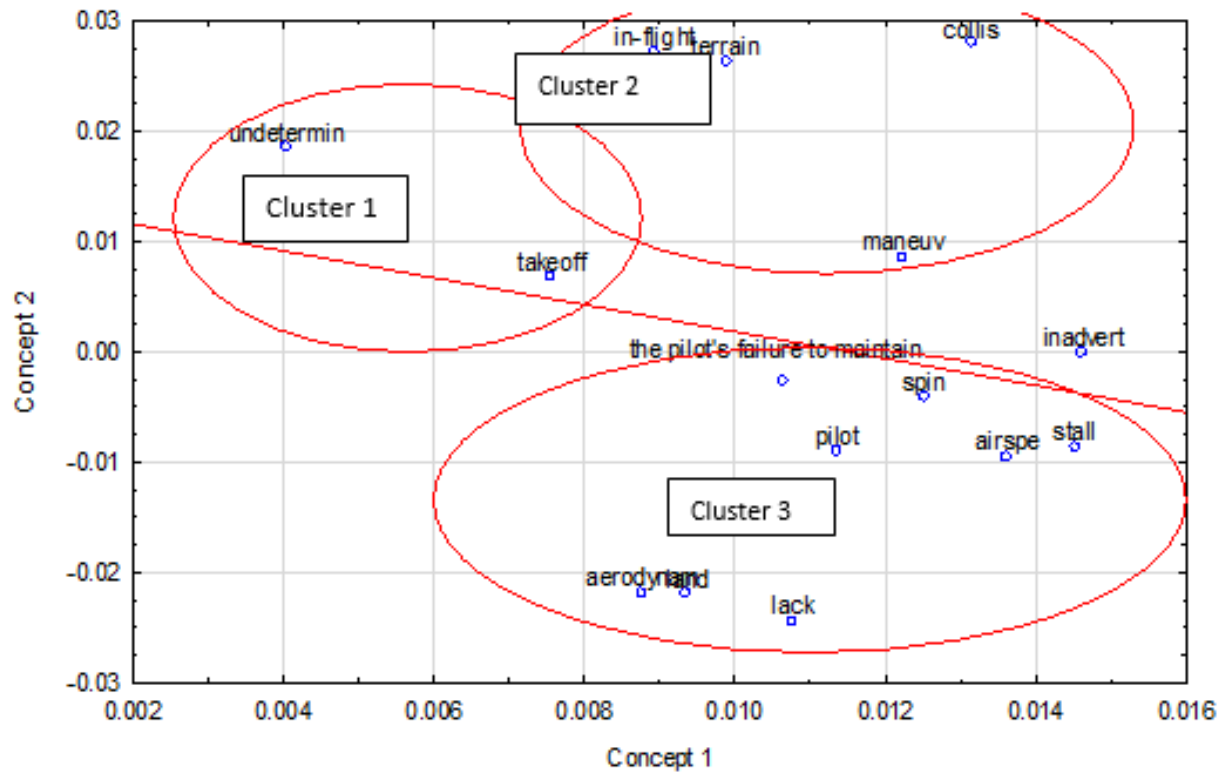

Figure 6. Scatter plot with clusters for text mining analysis of E-AB LOC accidents -sample:266 narratives. 
Text mining analysis for LSA airplanes in which LOC was listed as a cause. A total of 75 narratives were analyzed. Figure 7 shows the scatter plot graph for the concepts extracted from the singular value decomposition. The scatter plot appears to have two well-defined clusters of words. Cluster 1 includes the words take-off, land, climb, student, instructor, and loss. This cluster is mostly associated with accidents involving the take-off, landing, and climb phases of flight involving instructional flight. Cluster 2 includes the words maneuver, airspeed, stall, aerodynamic, and inadvertent. This cluster is mostly associated with accidents involving maneuvers in which low airspeeds resulted in inadvertent aerodynamic stalls.

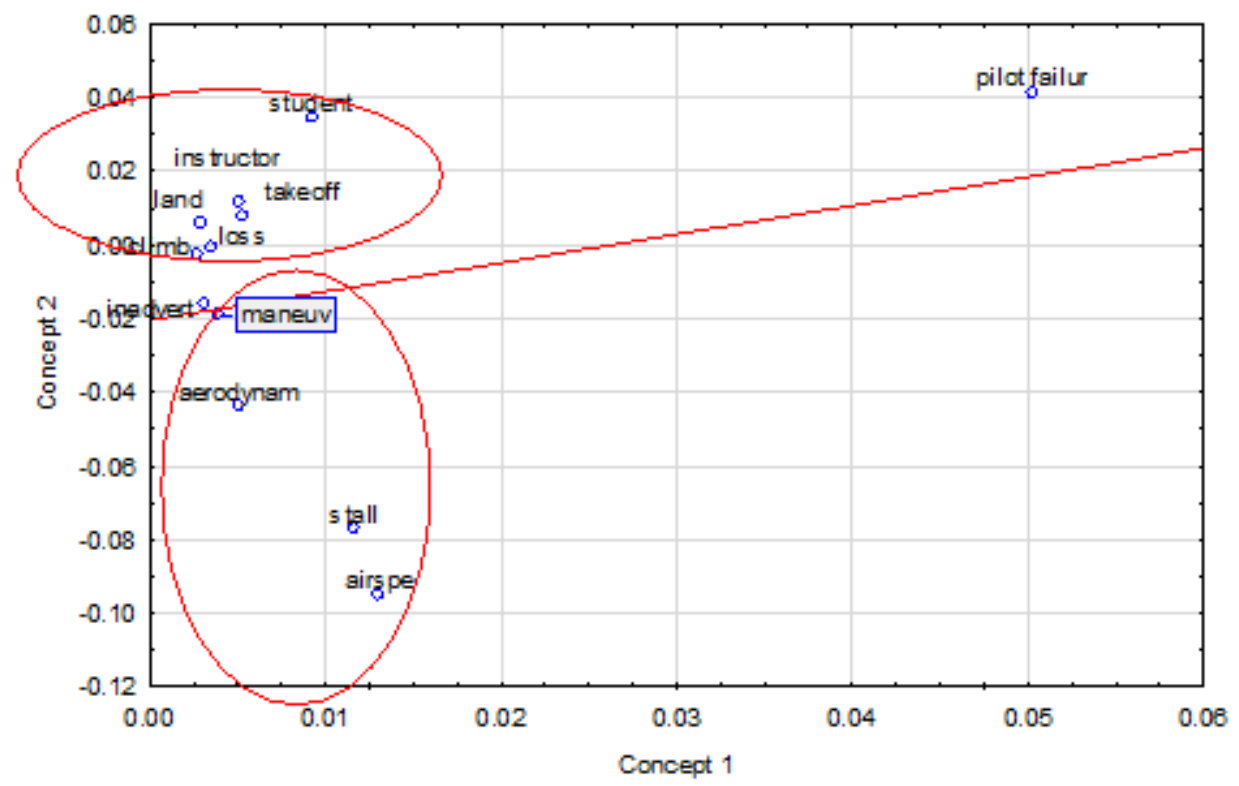

Figure 7. Scatter plot with clusters for text mining analysis of LSA LOC accidentssample:75 narratives.

Text mining analysis for CAR 3 airplanes in which LOC was listed as a cause. A total of 618 narratives were analyzed. Figure 8 shows the scatter plot graph for the concepts extracted from the singular value decomposition. The scatter plot appears to have two well-defined clusters of words. Cluster 1 includes the words: take-off, landing, stall, rudder, turbulence, departure, personnel, system, and maintenance. This cluster is mostly associated with accidents involving, take-offs, landings, systems, and maintenance issues. Cluster 2 includes the words cruise, weather, spatial disorientation, non-instrument, continued, night inadequate, lack, experience, decision, and dark (see Figures 9 and 10). After analyzing the narratives 
that contained the most important concepts, this cluster is mostly associated with accidents involving inclement weather, low visibility at night, and non-instrument rated pilots in VFR flight into IMC conditions.

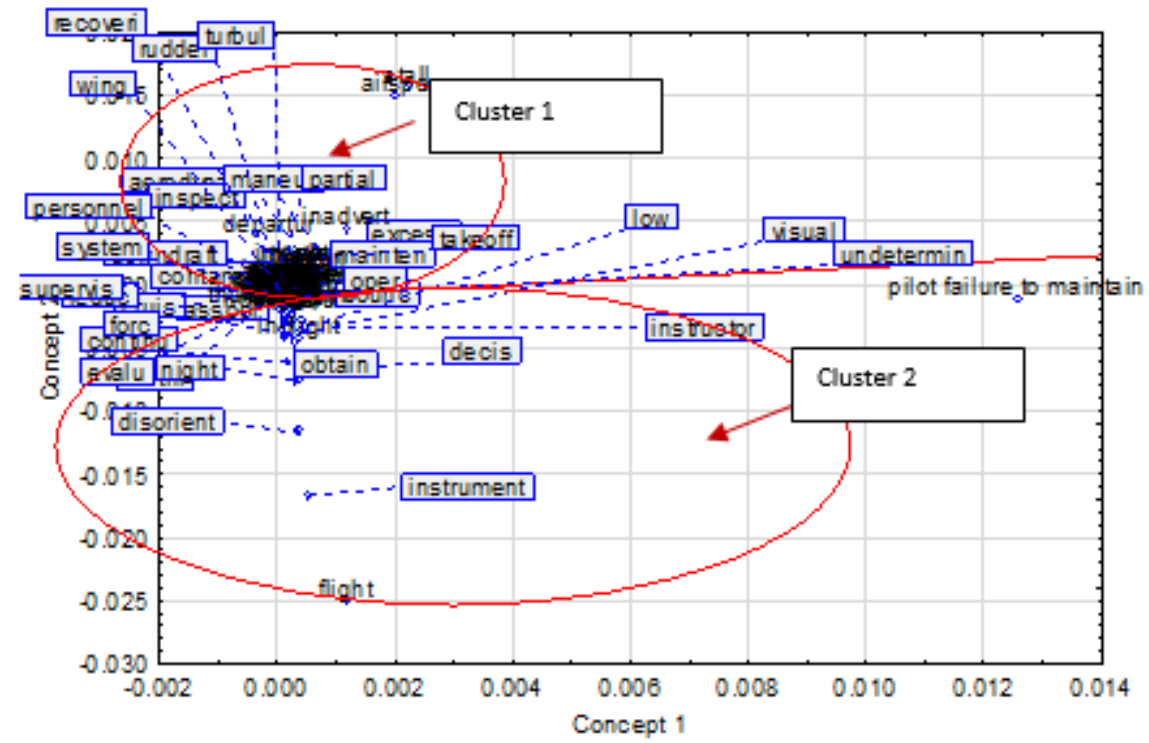

Figure 8. Scatter plot with clusters for text mining analysis of CAR 3 LOC accidents-sample: 618 narratives.

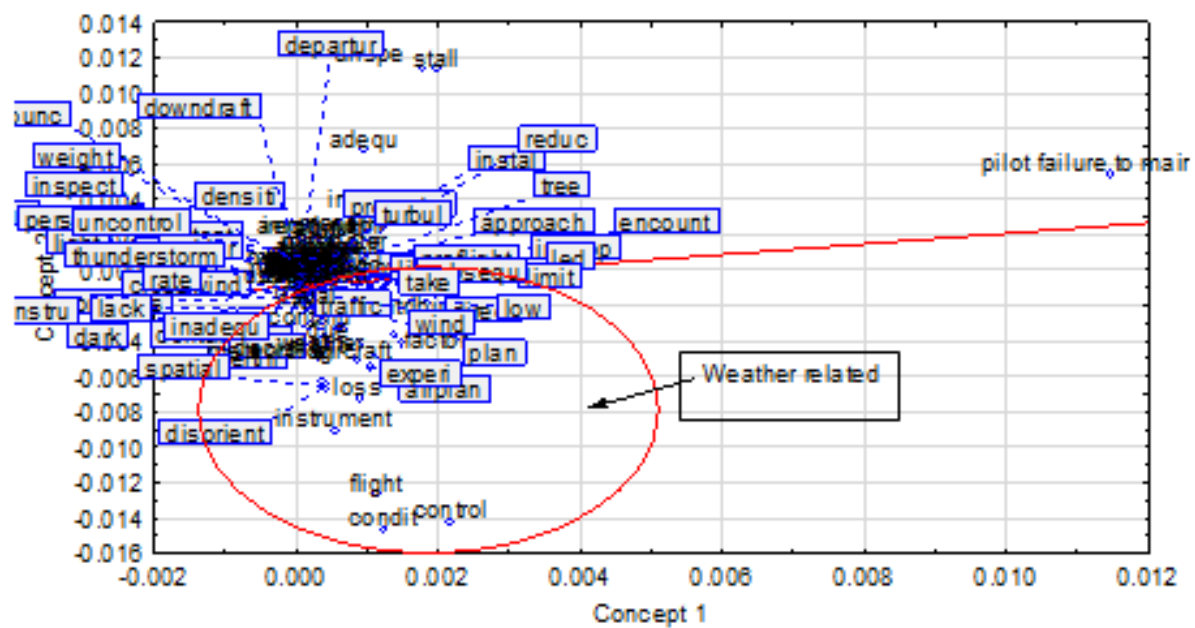

Figure 9. Detail of scatter plot with clusters for text mining analysis of CAR 3 LOC accidents. 


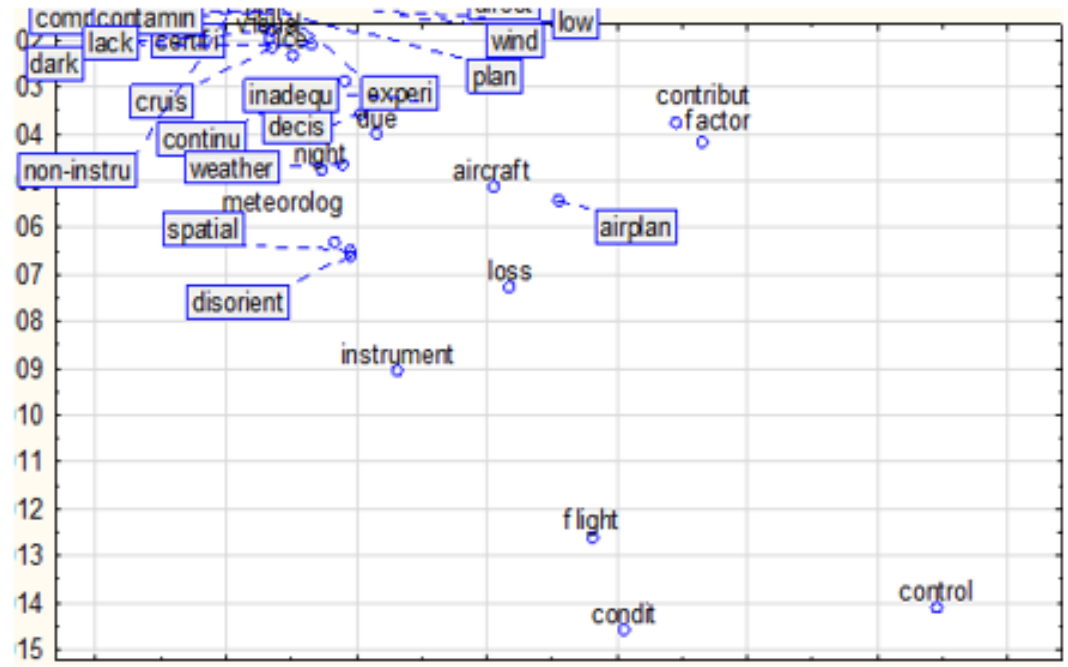

Figure 10. Detail of weather-related clusters for text mining analysis of CAR 3 LOC accidents.

Text mining analysis for Part 23 airplanes in which LOC was listed as a cause. A total of 196 narratives were analyzed. Figure 11 shows the scatter plot graph for the concepts extracted from the singular value decomposition. The scatter plot appears to have two well-defined clusters of words. Cluster 1 includes the words take-off, land, decision, maneuver, inadvertent low altitude, and decision. This cluster is mostly associated with accidents involving take-off, go-around, landing phases of flight, and low altitude maneuvering involving inadvertent spins in which the pilots' decision-making was a contributing factor. Over $9 \%$ of the accidents involved low altitude maneuvers. Cluster 2 includes the words special, disorientation, and instrument. This cluster is mostly associated with spatial disorientation in instrument meteorological conditions.

After conducting text mining analysis by certification basis for LOC accidents, the results indicated that E-AB and LSA airplanes did not have clusters of words associated with restricted visibility, degraded weather conditions, and VFR flights into IMC. Among LSA airplanes, some LOC accidents involved instruction during take-offs and landings. Part 23 aircraft showed a word cluster associated with spatial disorientation and instrument meteorological conditions. Airplanes in the CAR 3 group were represented by had a cluster related to reduced visibility, sub-optimal weather conditions, night, and flight into IMC. 


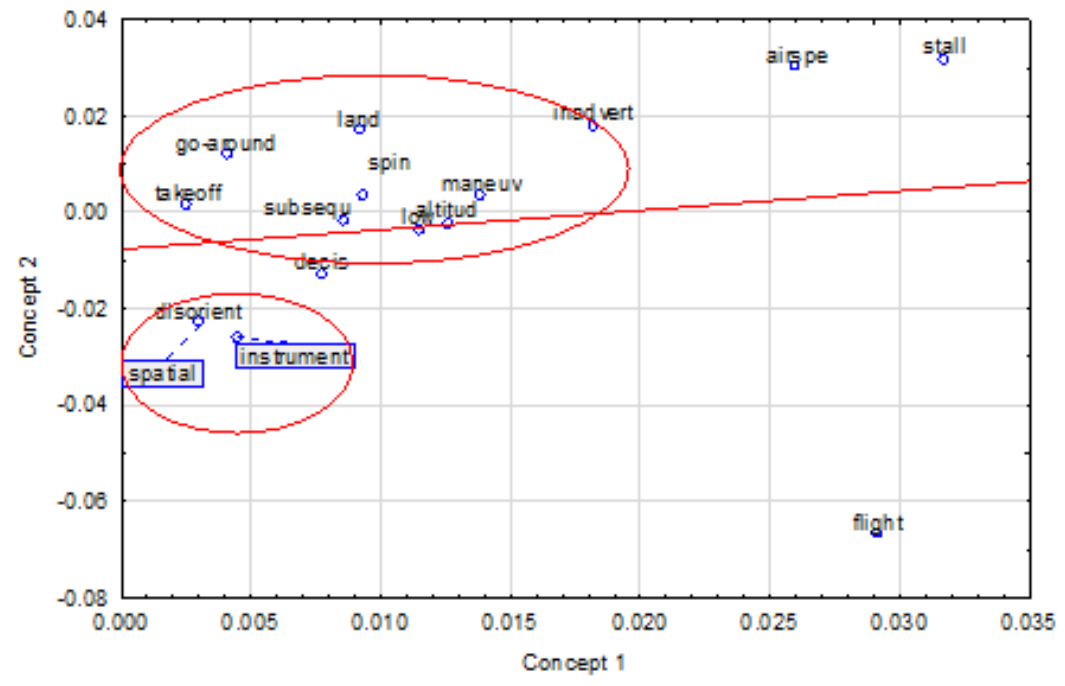

Figure 11. Scatter plot with clusters for text mining analysis of Part 23 LOC accidents-sample:196 narratives.

\section{Discussion}

The sample consisted of 1,155 LOC accidents. The number of accidents by certification category were: 618 accidents for CAR 3, 196 accidents for Part 23, 266 accidents for E-AB, 41 accidents for S-LSA, and 34 accidents for E-LSA. Text mining was used to analyze the narrative causes of accident reports. Only the narrative causes of accidents in which LOC was listed as a cause were analyzed. The first analysis of accidents in which LOC was listed as a cause for all aircraft certification categories indicated three main groups of words or clusters. The first and second clusters were associated with LOC during take-offs/ landings and maneuvering flight respectively. Reduced visibility, degraded weather conditions (unsure how degraded weather differs from reduced visibility) and VMC to IMC flight were associated with the third cluster. A cluster of words related to spatial disorientation and instrument flight segregated with accidents involving Part 23 accidents. The CAR 3 aircraft group had a cluster correlated with low visibility, poor weather conditions, night, and VFR flight into IMC conditions. In contrast, the E-AB and LSA airplanes did not show any clusters of words associated with the aforementioned hits. 


\section{Conclusions}

LOC accounted for 1,155 accidents, an accident rate of 0.99 per 100,000 hours flown, or $18 \%$ of all the accidents between 2004 and 2011, and is the number one cause of accidents in GA. These results are consistent with previous studies and support the need to focus on LOC prevention for GA to reduce the overall frequency of GA accidents and the accident rate (GAO, 2012; GAJSC, 2012; NTSB, 2012b). Airplanes certified under CAR 3 rules accounted for 53.5\% or 618 of the accidents in which LOC was listed as a cause and also accounted for $62.65 \%$ of the total accidents between 2004 and 2011. For Part 23 airplanes, there were 196 LOC accidents between 2004 and 2011, with a decreasing trend of 28 accidents in 2004 to 19 accidents in 2011 that represents a $32 \%$ decrease in seven years. For EAB airplanes, there were 266 LOC accidents between 2004 and 2011, with a decreasing trend of 41 accidents in 2004 to 19 accidents in 2011 that represents a $53 \%$ decrease in seven years. As expected, there was an increase in LOC accidents for the LSA category from 0 accidents in 2004 to 18 accidents in 2011 with a total of 75 LOC accidents between 2004 and 2011.

The results of the study indicated that GA aircraft certification rules are statistically linked with the frequency of LOC accidents but not with the mishap rate (Anderson, 2013). The results of this study indicate that the average pilot flight times did not differ substantially among the different certification categories; this result is supported by the literature. On the other hand, the literature also indicates that pilots of $\mathrm{E}-\mathrm{AB}$ accident aircraft, on average, had considerably less flight experience in the make and model of E AB airplane (NTSB, 2012b).

The text mining analysis of the qualitative portion of the accident reports showed that CAR 3 airplanes, unlike the other categories, were involved in LOC accidents associated with reduced visibility, degraded weather conditions, night, and continued VMC to IMC flights. CAR 3 airplanes were designed and manufactured prior to the 1960s thus representing the oldest airplanes in the GA fleet. CAR 3 airplanes in most cases have not been modified to harness newer safety-enhancing technologies that could mitigate LOC accidents. According to the literature, installation of autopilots in general aviation airplanes certified for IFR flight could reduce LOC accidents at night and in IMC by 50\% (GAJSC, 2012). With respect to LOC accidents, it appears that excessive government regulations likely have posed an impediment to the adoption of such new safety-enhancing equipment into legacy aircraft. 


\section{Recommendations}

To reduce the accident rate and the frequency of LOC accidents in GA it seems important to focus on the airplanes certified under CAR 3 rules for three reasons: (a) CAR 3 airplanes consist of the oldest airplanes in the GA fleet; (b) CAR 3 airplanes were designed and manufactured prior to the 1960s, and in most instances, have not been upgraded with newer technologies; and (c) the text mining analysis showed that CAR 3 airplanes were involved in LOC accidents associated with poor weather conditions and VFR flight into IMC conditions. The use of AOA indicators and autopilots to prevent LOC accidents should be assessed. The FAA should facilitate the retrofit of the legacy fleet with safety-enhancing technology if this technology proves to be helpful in the prevention of LOC accidents.

As indicated by the text mining analysis of the narrative cause of the mishap reports, the aircraft within each category are operated differently and have various needs; therefore, to reduce the number of LOC accidents in GA, each aircraft certification category must be addressed differently. The words found within each of the text mining clusters have indicated the emphasis areas where additional training, technology, or awareness should be placed to reduce LOC accidents. The CAR 3 airplanes have on average the largest number of hours on the airframe; however, the average pilot flight times do not differ substantially among any of the categories. As suggested in the literature, retrofitting these older airplanes to take advantage of new technologies might help in the reduction of LOC accidents. Based on the clusters of words revealed in the text mining analysis, the areas of emphasis to reduce LOC accidents among CAR 3 airplanes should be: (a) avoiding VFR flight into IMC, (b) aeronautical decision making, (c) pre-flight planning, and (d) traffic pattern work especially during instructional flights. To reduce LOC accidents among Part 23 airplanes, the areas of emphasis should be (a) traffic pattern work especially during instructional flights, and (b) spatial disorientation in instrument conditions. To reduce LOC accidents among the E-AB airplanes, the areas of emphasis should be (a) take-off, (b) landings, (c) maneuvering flight, and (d) low altitude maneuvering. To reduce LOC accidents among the LSA airplanes, the areas of emphasis should include (a) traffic pattern work especially during instructional flights, and (b) maneuvering flight. Advocacy groups like EAA and ASTM could be approached to disseminate information and conduct specialized training for each particular category, such as E-AB and LSA.

The adoption of consensus standards for GA aircraft certification could be an appealing alternative. As opposed to the way it is currently done in the LSA category where all the rules and forms of compliance are done utilizing industry consensus standards, it is recommended that basic performance-based safety requirements are kept within the Part 23 regulations, and the prescriptive methods 
and technology dependent guidance be removed from the FARs, changing the methods of compliance with industry consensus standards. Applying consensus standards has the potential of simplifying the retrofit of the legacy fleet of GA airplanes to encourage the installation of safety enhancements in a timely and economically viable way. As supported by the literature, a risk management approach should be taken to analyze whether the current certification regulations are actually an impediment to installing safety-enhancing equipment into the GA fleet (GAJSC, 2012). Installing autopilots and AOA indicators on a certified airplane could cost between five to ten times more than installing these devices on an experimental airplane, which could represent between 10 to $50 \%$ of the average value of a GA airplane (GAJSC, 2012). The risks and benefits of installing autopilots and AOA indicators in older aircraft without a rigorous, expensive, and time-consuming certification process should be assessed.

\section{Acknowledgement}

I would like to thank Dr. Douglas Boyd for his technical editing and assistance with proofreading. 


\section{References}

Airworthiness Standards for Normal, Utility, Acrobatic, and Commuter Category Airplanes. Notice of Proposed Rulemaking. Federal Register Number: 2016-05493. Docket ID: FAA-2015-1621. (March 14, 2016). Retrieved from https://www.regulations.gov/\#!documentDetail;D=FAA-2015-16210003

American Society for Testing and Materials. (2012). ASTM overview. Retrieved from http://www.astm.org/ABOUT/overview.html

Anderson, C. (2013). The effects of aircraft certification rules on general aviation accidents (doctoral dissertation). ERAU, Daytona Beach, FL.

Anderson, C. L. (2015). The effects of aircraft certification rules on general aviation accidents, Journal of Aviation Technology and Engineering, 4(2), Article 7. http://dx.doi.org/10.7771/2159-6670.1104

Bowles, G. (2010). Small airplanes [PowerPoint slides]. Retrieved from http://www.faa.gov/news/conferences_events/2010_us_eu/conference_mat erials/media/ComplexSmallAircraftGAMA.pdf

Committee on Aircraft Certification Safety Management. (1998). Improving the continued airworthiness of civil aircraft. Washington, DC: National Academy Press.

Federal Aviation Administration. (2009). Part 23-small airplane certification process study. Retrieved from https://www.faa.gov/about/office_org/headquarters_offices/avs/offices/air/ directorates_field/small_airplanes/media/CPS_Part_23.pdf

Federal Aviation Administration. (2011a). Airmen transition to experimental or unfamiliar aircraft (Federal Aviation Administration Advisory Circular No. 90-109). U.S. Department of Transportation, Federal Aviation Administration. Washington, DC: U.S. Government Printing Office.

Federal Aviation Administration. (2011b). Part 23 reorganization ARC charter. Retrieved from http://www.faa.govregulations_policies/rulemaking/committees/ documents/media/Part23Reorg.ARC.Cht.8-15-2011.pdf 
Federal Aviation Administration Aeronautics and Space, 14 C.F.R. (2013).

Field, A. (2009). Discovering statistics using SPSS. Thousand Oaks, CA: Sage Publications.

General Aviation Joint Steering Committee. (2012). Loss of control group approach and landing. Retrieved from http://www.avweb.com/pdf/ faaaopaaoareport.pdf

General Aviation Manufacturers Association. (2012). General aviation statistical databook and industry outlook. Retrieved from http://www.gama.aero/media-center/industry-facts-and-statistics/

Johnson, D. (2013). S-LSA aircraft list. Retrieved from http://bydanjohnson.com

McClellan, M. (2013, February). How to check out in an E-AB. EAA Sport Aviation, 62(2), 53-57.

National Technology Transfer and Advancement Act of 1995, Pub. No. L.104113, 5 Stat 552 (1996).

National Transportation Safety Board. (2012a). Review of aircraft accident data 2010. Washington, DC: Government Printing Office. Retrieved from http://www.ntsb.gov/doclib/reports/2012/ARA1201.pdf

National Transportation Safety Board. (2012b). The safety of experimental amateur-built aircraft. Washington, DC: Government Printing Office.

National Transportation Safety Board. (2013). Aviation accident database. [Data file]. Retrieved from http://www.ntsb.gov/doclib/reports/2012/ ARA1201.pdf

Nisbet, R., Elder, J., \& Miner, G. (2009). Statistical analysis and data mining applications. ( $1^{\text {st }}$ ed.). Burlington, MA: Elsevier.

Part 23 Aviation Rulemaking Committee. (2012). Regulatory structure working group summary and ASTM F44 committee guidelines. Unpublished manuscript.

Pompeo, M. (2013, May 6). [Letter to GAMA]. Copy sent to Part 23 ARC members. 
Shetty, K., \& Hansman, J. (2012). Current and historical trends in general aviation in the United States (Report No. ICAT 2012-6). Cambridge, MA: MIT International Center for Air Transportation.

Stephens, C. (2012). Status of the GAJSC and development of the forensic data analysis process [PPT presentation]. Retrieved from http://www.cgar.org/Meeting_2011/ GA\%20JSC\%20Activity\%20Update.pdf

Teddie, C., \& Tashakkori, A. (2009). Foundations of mixed methods research: Integrating quantitative and qualitative approaches in the social and behavioral sciences. Thousand Oaks, CA: Sage Publications.

U.S. Government Accountability Office. (2012). General aviation safety (GAO 13-36). Washington DC. Retrieved from http://www.gao.gov/assets/ 650/649219.pdf 